\title{
LAS CONDICIONES DE LA CIUDADANÍA
}

Juan Castillo Vegas ${ }^{1}$

\section{RESUMEN}

Los tres significados del término ciudadanía están profundamente interrelacionados. Ciudadanía como conjunto de ciudadanos y como derechos de los ciudadanos, dependen (en cuanto a su respeto social) de la ciudadanía como cualidades cívicas de los ciudadanos. Los derechos fundamentales de los ciudadanos son inherentes a ellos mismos como personas humanas pero requieren de complejos paradigmas y esquemas ético-jurídicos para conseguir ser respetados. La juridicidad propia de los derechos de los ciudadanos depende conceptualmente de la moralidad y de la racionalidad de los sujetos humanos. La ciudadanía política y social, que son aspectos de la ciudadanía jurídica, están condicionadas por la racionalidad y moralidad de los miembros de la comunidad política.

Palabras clave: Ciudadanía. Comunidad política. Derechos. Racionalidad. Moralidad.

\section{INTRODUCCIÓN}

Constantemente en la vida humana vemos cómo se pretenden los fines pero no se ponen los medios adecuados para la consecución de esos fines. Esto sucede en todos los ámbitos, también en el político-jurídico. Se pretende conseguir la paz, la ciudadanía (en cuanto cualidades propias del ciudadano), el respeto de los derechos humanos, pero no sólo no se crean las causas sino que frecuentemente se camina en sentido contrario y la paz no se consigue. No se consigue la convivencia justa, pacífica y democrática y en vez de respeto de los derechos humanos asistimos constante y dramáticamente a su quebrantamiento. Esta materia es sumamente delicada y podemos y debemos aplicar a ella el principio clásico: para que todo vaya bien, para que todo sea perfecto, deben concurrir todas las causas; para que todo vaya mal, basta un solo motivo.

La ciudadanía, la paz y los derechos humanos son el resultado de innumerables causas, con la particularidad de que si no se dan todas a la vez no se consigue nada.

Respecto a las condiciones generales de estos resultados (paz, ciudadanía, respeto de los derechos humanos) establecemos el siguiente esquema: racionalidad, moralidad, juridicidad. Pretender directa y exclusivamente el tercer término de la tríada: la juridicidad (paz, ciudadanía, derechos humanos), pero sin sus condiciones necesarias: la racionalidad y la moralidad, termina siendo ineficaz por definición porque en los contenidos del 
Derecho, aunque no en las definiciones usuales, están también la razón y la ética.

No entramos aquí en el tema clásico de la relación entre Moral y Derecho, denominado el cabo de las tormentas, por haber naufragado en su solución no pocas teorías. Ni tampoco en la diversidad de doctrinas: distinción, separación, absorción de la Moral por el Derecho o del Derecho por la Moral, etc. Sólo nos detenemos en una cuestión importantísima y a la que no se le ha prestado la debida atención, y es la siguiente: en el esquema racionalidad, moralidad, juridicidad, que son factores que van de género a especie, las especies incluyen, o mejor, deben incluir los géneros, bajo pena de anularse o vaciarse a sí mismas. Así la moralidad, como especie de la racionalidad, debe incluir ésta como su género. Y la juridicidad como especie debe incluir también los dos géneros anteriores: la moralidad y la racionalidad. Se podría objetar a esta tesis que la juridicidad, el Derecho, es una especie distinta, autónoma, independiente de la Moral. Objeción admisible teóricamente, desde una estricta ciencia del Derecho, pero en la práctica, en la vida social, política y jurídica tienen mucha relación. O lo que es lo mismo: entre las motivaciones personales en el cumplimiento de las normas jurídicas pueden no estar incluidas las motivaciones morales. El Derecho puede ser cumplido sin motivaciones morales; incluso exigirlas expresamente por el legislador sería, paradójicamente, la negación de ambos: del Derecho y de la Moral. Admitido también. Pero lo cierto es que: a) la Moral sería una razón más para cumplir el Derecho; b) muchas normas jurídicas en las que existe la posibilidad de eludir la sanción penal, no se cumplen sin razones morales. Un ejemplo claro, entre muchos, es la ecología, materia y ámbito en que no es posible controlar siempre y en todo a todos los ciudadanos; c) el convencimiento moral sería la más poderosa razón jurídica, es decir, con resultados positivos en el cumplimiento de la ley; d) las estadísticas demuestran que sin convicción moral existen grandes sectores, social-jurídicos, en que el Derecho no se cumple. Ejemplos palmarios son, entre otros muchos, el fraude fiscal y la frecuente inobservancia de las leyes de tráfico.

Acerca de la racionalidad de los derechos o del Derecho han existido polémicas históricas. Una de estas polémicas clásicas es la referente a qué es la razón o lo racional o lo natural en la conducta humana. Si preguntamos, por ejemplo, si la tendencia a mentir es racional, natural, pasional, instintiva, etc., encontramos dos posibles respuestas.

$\left.1^{\mathrm{a}}\right)$ Parece natural y profundamente arraigada en la naturaleza humana además de costumbre sumamente frecuente en el comportamiento humano. Según J. Schumpeter "el hombre, por su interés o por su ambición, lo primero que hace es mentir".

$\left.2^{a}\right)$ La tendencia a mentir es específicamente pasional e instintiva pero no racional o natural. Esta es la respuesta correcta. La inteligencia es la facultad del ser y de la verdad. Conoce el ser y la verdad. En segundo lugar, la misma inteligencia ordena decir la verdad conocida, no lo contrario de la verdad, ser, objeto o proposición pensados. 
Según R. Stammler: "Es engañoso creer que nuestros sentidos nos informan mejor sobre la legitimidad de las leyes naturales que sobre las leyes que rigen el deber. La simple percepción de los sentidos no basta para darnos conocimiento de una ley; esto solo lo puede hacer la inteligencia ordenadora" (Stammler, 2007, 340-341).

También John Rawls entiende que la moralidad es una forma de la racionalidad: "La suposición especial que hago es la de que a un individuo racional no le asalta la envidia. No es de los que están dispuestos a aceptar una pérdida para sí sólo en el caso de que los demás la tengan también" (Rawls, 1979, 170). O también: "Una razón para proceder así es que la envidia tiende a hacer peores a todos los hombres. En este sentido es una desventaja para la totalidad" (Rawls, 1979, 171). Para mayor claridad podemos completar estos principios de J. Rawls mediante este otro principio de un autor antiguo: "Ama la unidad y nunca tendrás envidia", lo cual significa que si prudentemente pensamos que todo bien y mal de los demás repercute en nuestro propio bien y mal nunca desearíamos el mal de nadie.

Una conclusión es, pues, que todo lo inmoral que afecte a lo social repercute negativamente en el sistema de fines racionales, aunque no necesariamente en el ámbito jurídico.

Asumir compromisos (contratos, pactos, tratados) a sabiendas de que no se pueden cumplir es también al mismo tiempo irracional, inmoral y antijurídico (si afecta al mundo del Derecho).

No hay ámbito de la ciudadanía que pueda desvincularse de la racionalidad y de la moralidad, en cambio no toda la racionalidad y la moralidad pertenecen a la juridicidad. Algunos de estos ámbitos (entre otros) son señalados por Antonio J. Colom Cañellas y Juan C. Rincón Verdera:

\footnotetext{
Educación cívica y valores educativos en tiempos de crisis, ciudadanía, democracia como moral, Estado de Justicia Social y transversalidad.

Educación para la paz y la no violencia, la participación y la solidaridad: civilidad y resolución pacífica de conflictos.

Educación para el desarrollo sostenible: ambientalismo, ecologismo y globalización. (Colom y Rincón, 2007, p. 202).
}

También C. Naval Durán destaca la conexión moral-educación en los derechos humanos: "Poner los derechos humanos como fuente ética de la educación cívica no determina cómo realizar ésta prácticamente, pero sí somete a juicio a esas prácticas en nombre de los derechos que la fundamentan. En distintos documentos de la UNESCO queda claro que la educación en los Derechos Humanos se convierte en una educación moral y cívica que se refiere a las relaciones de los ciudadanos con la sociedad y de las sociedades entre sí" (Naval Durán, 2000, 49-50).

Conceptos como dignidad de la persona y derechos humanos contienen claramente los tres aspectos: racional-moral-jurídico. El principio: no privar de la razón, que es uno de los menos negados en la historia cultural del mundo, 
integra también los tres aspectos.

También la división clásica de los bienes: agradables, útiles y morales nos conduce directamente a la racionalidad. El bien moral es el bien racional, intelectual, en sí mismo y por sí mismo, aunque no sea agradable ni útil. Las cualidades y las enfermedades de la racionalidad se transmiten a la moralidad y las de ésta a la juridicidad, que ya tiene las suyas propias. Lo mismo que las cualidades y enfermedades de la razón se transmiten a la voluntad que ya tiene las propias.

Es conocida la opinión según la cual la propensión de la juventud a las drogas se debe al desprestigio de la razón entre los jóvenes. En esta materia están directamente implicados los tres factores: racionalidad, moralidad y juridicidad.

\section{LA RACIONALIDAD}

El concepto clave del Derecho es la racionalidad, no es la voluntariedad o la libertad. Estos son necesarios pero no son suficientes sin la racionalidad. La razón ha de estar siempre presente pero las otras facultades o cualidades a veces no:

$1^{\circ}$. En el imperativo racional de la ley moral natural intervienen las dos facultades propiamente humanas: la razón y la voluntad libre, pero más intensamente la razón. El acto de imperio, que es la esencia de toda ley, norma o precepto, corresponde principalmente a la razón, aunque, como acto humano que es, intervengan también en su ejecución el resto de las facultades propiamente humanas.

2 . Muchos derechos fundamentales son irrenunciables e indisponibles por su propio titular. Pertenecen, por tanto, a la razón más propiamente que a la voluntad libre, aunque también pertenecen a ésta. La libertad no es contradictoria ni con la obligatoriedad ni con la necesidad, en el caso de que se consienta con ésta. Precisamente una de las definiciones de la libertad es ésta: libertad es consentir con la necesidad.

$3^{\circ}$. Al consenso social no le corresponde cualquier clase de materia. Le corresponden cuestiones políticas, económicas, sociales, etc. En cambio, quedan excluidas por su propio carácter otras materias: lógicas, matemáticas, históricas, religiosas y las fundamentales de la Moral y del Derecho.

$4^{\circ}$. En el gobernante la arbitrariedad es rechazable, está fuera de la racionalidad.

5‥ La función kantiana del Derecho que consiste en compaginar libertades es importantísima, sin embargo no abarca el Derecho en su totalidad, a no ser en sentido amplísimo.

6ํ․ El concepto de deber tiene también un carácter intensamente racional 
que se pone de manifiesto principalmente en el caso de que su contenido sea sumamente desagradable, como, por ejemplo, pagar deudas. No siempre es agradable ser justo, pero la justicia pertenece de suyo a los bienes intelectuales, no a los agradables o útiles.

R. Zapata Barrero pone de relieve los deberes, no sólo los derechos, como integrantes del concepto de ciudadanía: "La pregunta básica que se plantea en este contexto es: ¿qué criterios deben orientar la educación de la futura ciudadanía? La tesis principal de la obra de Heater es que la ciudadanía implica una multidimensionalidad, esto es, elementos de identidad, virtudes, actitudes legales y civiles, obligaciones y deberes políticos y sociales en niveles locales y provinciales, nacionales, continentales e incluso mundiales. El autor sugiere que la educación de la ciudadanía tiene que recoger esta multiplicidad de dimensiones orientando la tarea según tres criterios principales: pericia, actitud y conocimiento (Zapata Barrero, 1996, 314-347). La intencionalidad del autor es doble: por un lado, el enfoque comentado de la relación entre educación y ciudadanía; por otro lado, su interés por subrayar la necesidad de introducir en el sistema educativo "una dimensión cosmopolita de la ciudadanía" (Zapata Barrero, 1996, 130).

7․ Obligación de los ciudadanos de consensuar los contenidos mínimos de una vida justa, pacífica, y democrática. No es contradictorio con lo anterior, pues existe libertad para acordar dichos contenidos mínimos pero no para excluirlos.

8․․ La facultad primera es la razón, y en el Derecho no tendrían derecho, no sería justo que otras facultades como la voluntad libre tuvieran prioridad lógica sobre ella o prioridad en la categoría y dignidad. No es racional que la razón no sea la primera. Por tanto puede haber consensos, consentimientos, libertades, voluntades, acuerdos, decisiones privadas, contratos, tratados, pactos, etc., irracionales. En este caso no son justos, porque la racionalidad es un elemento necesario de la justicia, mientras que la voluntad libre sólo es elemento necesario de la justicia en algunos casos, como en algunos derechos (no en los indisponibles) y en algunos deberes: los que uno acepte de buen grado, pero no en otros que uno no quiera aceptar pero que en razón, justicia y Derecho deba aceptar.

9․ La ley es una ordenación de la razón. La corriente de pensamiento intelectualista prevalece sobre la voluntarista que ha sido siempre el origen de dictaduras, injusticias y arbitrariedades.

10․ Fuera de la razón uno no tiene razón. Si alguien se opone a nuestra razón nosotros podemos oponernos a su voluntad. Podríamos contraargumentar: también el juicio sobre lo que es racional podría ser subjetivo, arbitrario y voluntarista. Respondemos que los valores superiores de la escala jerárquica, entre los que están los jurídico-morales fundamentales son los más objetivos. Así se los ha considerado siempre y está de acuerdo la escuela objetivista de los valores (E. Husserl, M. Scheler, N. Hartmann). Si no podemos conocer con certeza ni los más mínimos valores ético-jurídicos, ni siquiera los principios fundamentales, entraríamos en el escepticismo absoluto. 
En este caso todo el pensamiento ético-jurídico giraría sobre sí mismo como también todo el pensamiento teórico-especulativo cuando se niega el principio de contradicción.

El Derecho y la justicia son juicios del entendimiento o de la razón acerca del ejercicio de la libertad propia y de los demás. No es cierto que la libertad sea la principal facultad humana. Además no es una facultad, sino una cualidad de una facultad que es la voluntad y ésta es un apetito racional, es decir: la voluntad sin la razón solamente sería una facultad ciega. Entender que la libertad es la principal propiedad o facultad humana es un juicio erróneo del entendimiento. Éste es antes, es decir, la facultad que conoce la verdad y el bien antes de poder buscarlos o apetecerlos. Una facultad cognoscitiva es anterior en el tiempo a una facultad apetitiva. En cuanto a la prioridad en la excelencia, las dos facultades, la razón y la voluntad libre, serían similares en la necesidad y unidad de la persona. La libertad es el modo racional de elegir y practicar la verdad y el bien, y la razón y la verdad son la causa de la libertad. En sentido filosófico la verdad es la causa de la libertad. En sentido político, además de que la verdad (en la comunidad política, en los medios de comunicación, en la enseñanza) es la causa de la libertad (además lo político, como un aspecto de lo jurídico supone lo filosófico o racional o al menos lo razonable), también la libertad es causa de la verdad (sin libertad desaparece la verdad y sólo se comunica o enseña la falsedad).

\section{LA MORALIDAD}

La Moral y el Derecho no corresponden a la razón especulativa sino a la razón práctica, como pone de manifiesto J. M. Martínez Doral: "Pasemos ahora al conocimiento práctico y veremos cómo cambia el panorama; la finalidad misma de este conocimiento ya no es ver, "hacer patente el ser a la mirada del espíritu". Se trata de conocer, pero en función de la actividad y la conducta, no de captar esencias sino de dirigir la acción humana. El esfuerzo creador tiene ahora otra meta: el modo de orientar la acción del hombre en el cumplimiento de las múltiples tareas de la vida. Si conocemos, no es para descansar en el conocimiento y gozar en la contemplación de la verdad, sino para servirnos de ese conocimiento con miras a la acción" (Martínez Doral, 1988, 137).

En cuanto a la moralidad nos dice J. A. Ramos Pascua: "Al fundamentar el deber o la obligación jurídica, la moral legitima o justifica el sistema jurídico, aportándole un elemento de vital importancia: la estabilidad. Ningún orden jurídico podría gozar de estabilidad, ni siquiera subsistir durante mucho tiempo, si sus normas fueran cumplidas, no por convicción, no por su aceptación como modelos de conducta vinculantes, sino únicamente por miedo a las sanciones. Ningún sistema de normas que se apoye sólo en el miedo o en la fuerza es viable. De ahí la necesidad de la legitimación moral. Luego, del mismo modo que decíamos antes que el Derecho, al propiciar la paz, el orden y la libertad externa hace posible la moralidad, tenemos que asumir ahora la afirmación inversa o simétrica. También la moral, al fundamentar el deber de cumplir las exigencias del derecho, lo legitima y le proporciona la necesaria estabilidad que 
hace posible su mantenimiento. En otras palabras, la moral hace al sistema jurídico viable" (Ramos Pascua, 2007, 31).

Nunca se insistirá lo bastante en la relación entre la fundamentación racional del Derecho en la Moral y la motivación moral del cumplimiento del Derecho.

No faltan autores que rechazan la obligatoriedad moral de la obediencia al Derecho. Pero algunas de las razones que dan para defender su tesis son un círculo vicioso: debemos obedecer al Derecho porque si como ciudadanos nos beneficiamos de los efectos políticos, económicos y sociales del ordenamiento jurídico debemos corresponder con la práctica de la ley en legítima reciprocidad, lealtad y gratitud. Estas apelaciones al agradecimiento cívicosocial y al destierro del egoismo son ya típicamente morales.

En cambio, la acusación de círculo vicioso a la teoría que propugna la obediencia al Derecho por razones morales a condición de que sea justo no es correcta. La razón es la siguiente: si el Derecho es justo existen los dos deberes, moral y jurídico, de obediencia al Derecho. En cambio, si el Derecho es injusto, no existe ningún deber, ni jurídico ni moral de obedecerlo. En el concepto de justicia se da la interconexión de los dos ámbitos, puesto que el término justicia tiene diferentes significados: virtud moral, objeto del Derecho, estado social, político, económico, etc. El concepto de justificación de una norma jurídica es menos ambiguo que el de legitimidad y éste menos que el de validez.

Como es sabido la solución más comúnmente admitida en el problema del Derecho injusto es la siguiente: si es gravemente injusto (cuando afecta a los derechos fundamentales propios o de terceros no sólo no existe el deber de obedecerlo sino que debe ser positivamente desobedecido. En cambio, si es levemente injusto (cuando no afecta a los derechos fundamentales), existe libertad para cumplirlo o no, y puede, por tanto, obedecerse para evitar males mayores propios o de terceros.

Precisamente es en el término-concepto de validez con su polisemia (sentido jurídico, social y moral), donde se plantea la polémica clásica. A. Schopenhauer sostenía que la convicción moral-interna es la mejor de las razones de obediencia al Derecho. Muy superior a la razón penal (temor a la sanción del código penal), y a la sanción social (temor a la vindicta-vergüenza pública).

La fundamentación del Derecho en la Moral implica también la fundamentación del deber jurídico en el deber moral, aunque son deberes específicamente distintos. El fin tiene relación con la esencia-naturaleza de las cosas. Según Aristóteles la causa final es la causa de las causas, lo cual es equivalente al actual y pedagógico principio de que el fin crea los motivos. El fin de la Moral (la perfección de la persona), es distinto del fin del Derecho (organizar la vida social), pero ambos están relacionados. El Derecho posibilita la práctica de la Moral (al menos de una parte de la moral pública y social), y la Moral motiva la práctica del Derecho. La Moral privada o personal, que no 
pertenece al ámbito jurídico, es otro problema.

Como es sabido, la Moral impone deberes para con uno mismo y el Derecho no. Aunque uno esté solo en el monte no le es lícito moralmente mutilarse, suicidarse, drogarse, etc., conductas que el Derecho no está legitimado para prohibir. Podríamos escribir tratados enteros sobre el tema de la distinción entre el hombre bueno y el ciudadano bueno, pero no cabe duda acerca de que siempre podemos afirmar que es muy difícil o imposible que el hombre que no es bueno sea siempre un ciudadano política-social-económica y jurídicamente correcto. La argumentación-ilustración de la antedicha afirmación sería realmente abrumadora en muchísimas cuestiones y ramas del Derecho, sobre todo, por ejemplo, en materias ecológicas, fiscales y de tráfico rodado.

La ética discursiva de J. Habermas tiene muchos aspectos vulnerables en los que no podemos detenernos aquí. Sin embargo según J. C. Velasco: "A pesar de las diferencias reseñadas (en su teoría de la ética discursiva) Habermas no desvincula completamente moral y derecho. Ambos se inscriben en el terreno de la razón práctica sin supeditaciones ontológicas ni reduccionismos positivistas". O también: "De ahí que la negativa a aceptar la autonomía total del sistema jurídico sea un elemento crucial que distancia la reflexión habermasiana sobre el Derecho no sólo del positivismo jurídico clásico, sino también del redivivo, por ejemplo, en la sociología jurídica de Niklas Luhmann" (Velasco, 2003, 78).

La referencia del Derecho a la Moral es casi constante, sobre todo en algunas ramas del Derecho, como observa J. A. Ramos Pascua: "También remiten tácitamente a la moral normas tales como la que prohíbe los tratos y penas crueles, inhumanos o degradantes, porque es la moral la que nos enseña qué debe considerarse cruel, inhumano o degradante" (Ramos Pascua, 2007, 32). Aparte de que casi todos los contenidos del Código penal pertenecen a ambas regulaciones, moral y jurídica. También aquí comprobamos la implicación recíproca de lo racional, lo moral y lo jurídico. Si lo racional es el carácter específico de la raza humana, lo inhumano atenta al mismo tiempo contra la razón, la moral y el derecho. Y concluye el mismo autor: "Por todo ello, cuando aquí nos remitimos, como trasfondo moral del Derecho, a las convicciones ético-políticas socialmente compartidas o dominantes en nuestras sociedades occidentales, no estamos presuponiendo que se trata de una moral puramente convencional o costumbrista. Se trata de una moral que tiene a su favor una fuerte presunción de racionalidad. No sólo la moral, sino en general la cultura occidental, que hoy es ya cultura global, se caracteriza por su compromiso insobornable con la racionalidad. Sus saberes, sus ideas y valores no se han adoptado por ser productos occidentales, sino por ser racionales, sea cual sea su origen o filiación; de tal modo que si se demostrara objetivamente la invalidez o falsedad de alguno, sería pronto abandonado y sustituido por el que se evidenciara superior. En definitiva, nuestra moral social es moral racional mientras no se demuestre lo contrario" (Ramos Pascua, 2007, 36).

Si a todo imperativo moral y jurídico se le calificara de producto meramente cultural se produciría la confusión de casi todas las ciencias: la 
filosofía, la Moral y el Derecho con la sociología, la psicología, la antropología, etc. En el mismo sentido afirman V. Zapatero y Ma embargo la diferenciación entre el Derecho y la Moral no puede significar la incomunicación entre ambos campos de la normatividad. Son normas diferentes que pueden estar íntimamente relacionadas en una doble dirección: porque se estima que el derecho debe ajustarse a parámetros morales 0 porque se mantiene que el Derecho debe proteger, amparar o legalizar comportamientos exigidos por algún tipo de moralidad" (Zapatero y Garrido, 2007, 31). Entre otras funciones, la Moral ejerce también una función crítica respecto al Derecho, como destacan los mismos autores: "Pero en ocasiones también utilizamos la moral para sostener que un sistema jurídico es justo o injusto, que debemos obedecer o no moralmente. Es decir, la pregunta sobre las relaciones entre el Derecho y la moral nos conduce a la de la legitimidad y la justicia de un sistema jurídico, a cuándo podemos decir que es legítimo y debemos moralmente obedecer sus normas, porque la legitimidad hace referencia a todo ese conjunto de valores, principios y procedimientos que intentan operar como justificación de las instituciones" (Zapatero y Garrido, 2007, 35).

Podríamos ahora distinguir los siguientes conceptos de lo moral en relación al Derecho:

1ํ. Lo moral como objeto de la razón práctica, género próximo del Derecho.

$2^{\circ}$. La Moral legislada en el mismo Derecho. Gran parte de los mandatos y prohibiciones de algunos códigos jurídicos pertenecen también a la Moral.

3‥ En relación con el número anterior: la Moral como el mínimo ético. La parte de la Moral que ha de ser jurídicamente imperativa. Sin este mínimo ético específicamente jurídico es imposible una vida social justa pacífica y democrática. A este respecto escribe R. Andorno: La expresión minimun ethicum pretende poner de relieve que el derecho no es un sistema cerrado, aséptico a los valores, sino que, por el contrario, encuentra su fundamento último en la ética, y en particular, en el primer principio de la razón práctica, que ordena hacer el bien y evitar el mal. El derecho no es, por tanto, un orden amoral, desde el momento que aspira a hacer justicia al hombre."(Andorno, 1998, 48).

4ํ. La Moral como motivación para el cumplimiento de la ley jurídica. Si existieran ya en los destinatarios del Derecho otras motivaciones para la práctica de la norma jurídica, la motivación moral se suma a todas ellas reforzándolas. Si no existiera ninguna otra motivación para cumplir la ley jurídica, la motivación moral tendría que suplir a todas, de lo contrario o bien no es propiamente moral o no es suficientemente intensa o es claramente inmoral la conducta (de conculcación de la norma jurídica supuestamente justa).

50. La Moral como instancia crítica ante el Derecho. Las apelaciones a la justicia, a la dignidad humana, a los derechos humanos para juzgar el Derecho vigente son al mismo tiempo racionales, morales y jurídicas. 
6‥ Hemos dicho que el Derecho es el mínimo ético exigible en la vida social, pero a partir del cual se abre un inmenso campo de posibilidades y opciones referentes a la moral de cada ciudadano hasta el maximum ético que cada uno elija libremente. Este máximun ético quedaría ya fuera y superpuesto al ámbito jurídico.

$7^{0}$. La distinción entre el mínimo ético y el máximo ético ha de ser neta desde el punto de vista racional, moral, jurídico, democrático, etc. En cambio debemos afirmar que en la perspectiva personal, sociológica, psicológica, cultural, vital, etc., tienen más relación de lo que pudiera parecer. El Derecho crea las condiciones políticas, económicas y sociales para que aquel que voluntariamente decida alcanzar su perfección moral lo pueda conseguir. Por consiguiente sin las condiciones del Derecho (paz, justicia, concordia, desarrollo, etc.), es muy difícil que la persona-ciudadano pueda conseguir una moral de máximos sin la plataforma de mínimos.

Una de las muchas definiciones de la libertad es poder querer lo que se debe ser. Pero si las condiciones sociales, políticas y económicas no son las adecuadas es muy difícil poder querer lo que se debe ser. No es imposible, pues la persona es siempre libre y responsable (mientras los condicionamientos de la libertad, que siempre existen, no alcancen una determinación absoluta). Dicho de otro modo: en unas condiciones jurídicosocial-políticas negativas se requerirían unas cualidades morales heroicas para alcanzar una moral de máximos. Ahora bien, el heroismo no se puede exigir a las masas, sólo se puede exigir o esperar de algunas personas selectas.

La imperatividad u obligatoriedad del Derecho es una especie de la obligatoriedad pero no la única. Hay otras especies de la obligatoriedad entre ellas la moral. La obligatoriedad es una especie de la racionalidad, pertenece a la razón práctica, es el principal contenido de la razón práctica que incluye la Moral y el Derecho. Según Kant (Crítica de la razón práctica) la ley moral y el imperativo categórico son un factum de la conciencia. Con más precisión podemos decir que son el objeto de una intuición intelectual de carácter moral.

Acerca de la evidencia de los primeros bienes, principios y valores señala J.C. Suárez Villegas: "La mejor manera de entender en qué sentido los bienes básicos son evidentes, sería comprenderlos como los puntos de llegada en los que se detiene la explicación de nuestros actos y captamos la razón por la que éstos tienen sentido. Su inderivabilidad no significa falta de justificación sino evidencia, pues nuestra razón los descubre como el fundamento inteligible que nos permite comprender lo que hacemos sin necesidad de ulteriores explicaciones" (Suárez Villegas, 1996, 69). Esto no significa que no hagan falta en materia moral deducciones subsiguientes. Al contrario, es la evidencia de las premisas la que hace posibles las demostraciones ciertas. La obligatoriedad moral del Derecho está también directamente relacionada con el bien común jurídico-político. El mismo autor añade: "La moralidad del medio para perseguir un fin estará en relación con la naturaleza de dicho fin, extremo tal que no queda asegurado porque algo sea mandado por el Derecho" (Suárez Villegas, 1996, 95). 
Sobre esta cuestión existe una importante polémica entre los que opinan que el Derecho tiene una relación esencial con la justicia y los que consideran que el Derecho es sólo un determinado medio para conseguir unos fines que, propiamente, no propone el Derecho, puesto que éste es sólo un determinado modo de realizarlos: el más eficaz socialmente, el coercitivo.

Es interesante comprobar cómo algunos autores rechazan la obligatoriedad moral para fundamentar la obligatoriedad jurídica, pero cuando ésta es incumplida o rechazada entonces apelan a la moral para vituperar a los desobedientes del Derecho: desvergüenza, ingratitud con la sociedad, conducta indigna, falta de reciprocidad en cuanto a los beneficios que reciben de la sociedad, etc. Incluso la indignación como sentimiento tiene mucha relación con la indignidad como trato, injusticia, situación, etc.

Desde una cuestión de permanente actualidad como es la ecología se vuelve actualmente de modo continuo a la moral principalmente mediante el principio de solidaridad que es un concepto fundamentalmente ético (Bellver Capella, 1994, 269). Sólo la ética, la razón práctica, la conciencia moral, pueden conseguir algunos fines especialmente dificultosos en materia ecológica. Entre ellos están fundamentar y educar en los derechos y en los deberes, no sólo garantizarlos, puesto que en muchos casos no es fácil o es imposible garantizarlos positivamente: quema intencionada de los bosques, arrojar residuos radiactivos o tóxicos en alta mar, etc. Un aspecto importantísimo de la garantía de los derechos está en una adecuada fundamentación filosófico-moral. Existe un principio que dice que para hacer el mal, todos somos muy poderosos, más que el Estado para evitarlo.

En cuanto a la fundamentación racional-moral de los derechos observa acertadamente C. I. Massini-Correas: "Es bien sabido que la debilidad de las premisas se traslada necesariamente a las conclusiones, y que, por lo tanto, si otorgamos a los derechos una fundamentación contingente y subjetiva, tendremos "derechos humanos" contingentes, es decir, no necesarios, y subjetivos, o sea, imposibles de imponer coherentemente a los otros sujetos jurídicos. Por otra parte, los sucedáneos inventados por los pensadores contemporáneos para paliar esta debilidad de fundamento -el más común de ellos es el "consenso"- no solucionan la cuestión y sólo pueden dar razón de unos derechos condicionados y relativos.... Dicho de otro modo, todos los ensayos de justificar los "derechos humanos" de modo meramente "procedimental" o "contractual" o "intersubjetivo", resultan estériles, ya que una fundamentación solo "plausible" o razonable, pero no estrictamente "racional" o "posible", tal como la que pueden otorgar esos procedimientos, deja a esos derechos -en última instancia - en manos de los mismos sujetos y asegurados por una obligatoriedad efímera y provisoria" (Massini-Correas, 1991, 265).

Los derechos se fundamentan en la dignidad de la persona y la dignidad en la razón y voluntad libre de la misma persona. La dignidad es la excelencia, rango, excelencia y categoría del sujeto racional y moral, que tiene también necesariamente su correspondiente reflejo y traslado al sujeto jurídico. En este 
mismo sentido escribe R. Spaemann: "Un derecho que puede ser anulado en cualquier momento por aquellos para los que ese derecho es fuente de obligaciones, no merece en absoluto el nombre de derecho" (Spaemann, 1988, 13-14).

R. Andorno, siguiendo a R. Spaemann, señala que la misma idea de derechos humanos implica que nadie está autorizado para decidir si otro individuo humano es un sujeto de derechos: "Por el contrario, es la sola pertenencia a la especie homo sapiens lo que debería determinar su status de persona. Cualquier otro criterio convertiría a algunos hombres en jueces de otros y la noción de derechos humanos quedaría suprimida de raíz" (Andorno, 1998, 70-71). Y concluye que no deben confundirse, obviamente, derechos con concesiones. No cabe duda que algunos derechos pueden ser concesiones del legislador, pero sería contradictorio que absolutamente todos los derechos fueran concesiones del legislador. Es evidente que muchos derechos no son concesiones voluntarias, magnánimas y gratuitas del legislador sino verdaderos derechos de los ciudadanos, es decir, auténticas facultades que implican una genuina capacidad de exigir determinados comportamientos.

En cuanto al complejo tema del aborto podemos distinguir, entre otras muchas, tres cuestiones. En primer lugar, la protección jurídica del no nacido: facilitar las adopciones, ayudar a las madres solteras, etc. En segundo lugar está la protección penal del no nacido: si se puede o se debe privar de libertad al que realice un aborto. Esta es, con mucho la cuestión más difícil y que no vamos a tratar aquí, como tampoco la anterior. En tercer lugar, está el aspecto moral del que vamos a hacer algunas consideraciones. Partimos de la base de que es gravemente inmoral y plantea graves problemas racionales, éticos y jurídicos: tienes todos los derechos si se te permite nacer, eres sujeto de derechos si se te permite ser sujeto de derechos. Existen tus derechos si se te permite existir. La condicionalidad absoluta de todos los derechos destruye todos los esquemas de la razón, de la Moral y del Derecho. Giran sobre sí mismos todos los parámetros de lo verdadero y de lo falso (racionalidad), de lo bueno y de lo malo (moralidad), y de lo justo y de lo injusto (juridicidad).

Cuando entra en crisis el sujeto racional entra también en crisis el sujeto moral y en consecuencia el ciudadano (el sujeto jurídico). Es contradictorio exigir todos los derechos, todos los respetos en el ámbito de la ciudadanía cuando se han destruido todos los derechos y todos los respetos en el ámbito del sujeto moral y del sujeto racional, hasta el punto de la destrucción misma de éste. Estaría todo condicionado a la existencia y ésta a la voluntad humana: debemos ser racionales si existimos, debemos ser buenos si existimos, debemos ser justos si existimos o nos permiten existir. Los demás tendrán todos los deberes y todos los derechos si les concedemos uno: el derecho a existir. De este modo no existiría ninguna imperatividad categórica. Todos los imperativos serían hipotéticos, condicionados, relativos, lo cual cambia la naturaleza de la razón práctica, de la Moral y del Derecho. No todos los derechos son absolutos pero si se excluyen absolutamente todos de esta calificación se cambia radicalmente el concepto mismo de derecho.

Tampoco una práctica puramente sociológica, fáctica o costumbrista 
parece el mejor de los argumentos para fundamentar la obligatoriedad jurídica nos dice J. C. Suárez Villegas: "No obstante, una práctica por sí misma no puede explicar por qué es obligatoria. En ocasiones, se ha argumentado, como hizo Hume, que la obligación del sujeto para con una práctica social radica en su propio interés, ya que de no hacerlo perdería la confianza de sus conciudadanos y se vería desahuciado por una práctica social que le era útil. Pero, si la prudencia y el interés personal fuese la razón para explicar la obligatoriedad de una práctica, no habría inconveniente en aceptar que para uno es mejor desobedecerla si no ve peligro en hacerlo y además obtiene un mayor beneficio personal. $Y$, si se dijese que no se puede violar porque es una práctica social, su violación sería la negación más clara de esa postura, ya que en tanto que es violada estaría dejando de ser una práctica social (Suárez Villegas, 1996, 99-100). El interés no puede ser nunca el fundamento último del Derecho, porque un interés determinado puede siempre ser contrarrestado por otro de superior intensidad.

También D. Hume pretendió fundamentar el Derecho y la justicia en los sentimientos: las conductas sociales que producen un sentimiento de agrado y aprobación serían justas; las que producen un sentimiento de desaprobación y de repulsión serían injustas. Sin embargo no puede admitirse esta fundamentación porque los sentimientos son ambiguos y unas veces favorecen la práctica de la justicia y otras la perjudican. Resultaría así una concepción puramente subjetivista de la justicia y todo aquel que temperamentalmente careciera de una adecuada estructura sentimental respecto de la justicia, quedaría paradójicamente justificado cualesquiera que fuese su comportamiento. Además la práctica de la justicia puede a veces inspirar sentimientos de repulsión cuando por las circunstancias que fueren sea difícil ser justo. Es la razón la que, en la práctica de la justicia, tiene que contrariar, si fuera necesario, sentimientos, pasiones, intereses que no la favorezcan. Un poeta medieval daba el siguiente consejo a los jueces: "Haced justicia sin amor, sin desamor, sin temor y sin codicia". Actualmente podemos ver resumidos e implicados en este consejo los principales principios del poder judicial: independencia, imparcialidad, neutralidad, etc.

Ya sabemos que la justicia absolutamente objetiva es imposible, pero si su mismo concepto está inapropiadamente configurado en cuanto a su origen, naturaleza, facultades y fines, mayor aún sería el alejamiento de la objetividad. Una de las muchas definiciones de la justicia es: la justicia es la verdad en acción. Es difícil realizar en la práctica esta definición. Pero si ni siquiera atribuimos la realización de la justicia a la facultad que tiene relación con la verdad que es la razón, la distorsión será realmente grave.

\section{LA JURIDICIDAD}

Entroncando con todo lo anterior situamos la siguiente máxima de $\mathrm{A}$. Einstein: "Las instituciones democráticas no son mejores que los individuos que las usan como instrumentos". El cambio en las estructuras políticas, económicas y sociales influye en el cambio personal de los ciudadanos, y el cambio de éstos influye también en la transformación de las estructuras. De 
aquí que no quepa duda de que una correcta formación-educación-instrucción de los ciudadanos influiría positivamente en el funcionamiento y la estabilidad del Estado social y democrático de Derecho y del Estado de bienestar.

El deber jurídico es distinto del deber moral, pero en algún aspecto es una especie de éste y no es fácil, por no decir imposible, tomar conciencia de deberes jurídicos el ciudadano que carece de conciencia de los principales deberes morales. A su vez, como ya conocemos, los deberes morales y jurídicos provienen de la razón práctica (conciencia moral, que es un modo de ejercicio del único entendimiento humano, no una facultad distinta), racionalidad que dirige las acciones humanas en relación al bien y al mal.

Jürgen Sprute resume esta distinción entre el deber jurídico y el moral: "Es cierto que el Estado puede obligar a sus ciudadanos al cumplimiento de los deberes jurídicos por medio de sanciones pero la coacción sólo se refiere al cumplimiento externo. El Estado no puede obligar a los ciudadanos a cumplir un precepto jurídico por convicción moral" (Sprute, 2008, 138).

Supongamos que rechazamos absolutamente este esquema teórico-ético y pretendemos explicar exclusivamente el deber jurídico. Parece que solamente podría derivar su origen bien de la nada, bien del consenso (en el que quedaría incluida la autoridad política democrática). Pero esta posición tiene innumerables inconvenientes. En primer lugar, de la nada significaría prescindir absolutamente del sujeto racional y moral. Si nos inclinamos por la segunda solución, el deber jurídico proviene exclusivamente del libre consenso del ciudadano y de los ciudadanos, tendríamos la completa disolución del genuino "deber", que se transformaría siempre en un "debo si quiero". El "debo si quiero" es válido para las obligaciones contractuales pero no para toda obligación jurídica o moral. Existen muchas obligaciones jurídicas que no son contractuales. Expresado de otro modo: el Derecho, en su fundamento y esencia, no consiste en un entendimiento entre los ciudadanos sino en el deber de entenderse. En esta fórmula del "deber de entendimiento" quedan una vez más incluidos explícitamente los tres factores antedichos: la racionalidad, la moralidad y la juridicidad.

De este modo los géneros quedan expresamente incluidos en la especie. Si se rechazan los géneros (racionalidad y moralidad), al exigir la especie (la juridicidad), entraríamos en constantes contradicciones y aporías: "debo si quiero", con lo que sólo serían admisibles la obligaciones contractuales. Si no se otorga el propio asentimiento al contrato jurídico-político-cívico quedaría excluida toda obligación jurídico-política.

Otra contradicción sería la necesidad de fundamentar la posibilidad de exigencia de deberes contractuales fuera de los parámetros de un sujeto racional y moral como son, entre otros, la dignidad (como sentimiento, no como el mayoritariamente aceptado como fundamento de los derechos humanos) y el honor en el cumplimiento de los deberes contraídos en el contrato socialjurídico-político. También debe considerarse que la libertad puede estar presente en muchas clases de necesidades y deberes, en otras no. Por ejemplo, quedan excluidas del ámbito de la libertad, entre otras, la necesidad 
lógica, la matemática y la denominada necesidad físico-natural.

Con todo lo analizado hasta ahora podemos comprender mejor lo expresado por J. A. Ramos Pascua: "Puesto que nos interesa investigar la ética o los principios de justicia internos al Derecho, conviene conocer previamente qué relación existe entre Derecho y justicia, pues sólo así sabremos si la presencia en el Derecho de valores morales o principios de justicia es casual, contingente, aleatoria o más bien necesaria y requerida por la lógica misma de las cosas" (Ramos Pascua, 2007, 21). También aquí podemos solucionar la polémica en torno a si el Derecho está relacionado por sí mismo con determinados fines y valores como la justicia o si sólo es un modo específico de consecución de determinados fines. En este último caso, el Derecho pertenecería a la razón instrumental o técnica, pero no a la razón práctica o moral, que es su facultad propia, como venimos propugnando.

No podemos detenernos aquí en el análisis de las perniciosas consecuencias de la atribución del Derecho a la razón instrumental o técnica en lugar de a la razón moral o práctica. Este es el origen de los distintos voluntarismos, utilitarismos, pragmatismos, etc.

En esta cuestión J. M. Martínez Doral considera lo siguiente: "Una función valorativa y crítica, ejercida no sólo en el sentido de la técnica sino en el sentido de la justicia, presupone el conocimiento de las finalidades últimas de la sociedad y de la vida humana. Sólo cuando se conoce el fin puede juzgarse si los medios arbitrados para conseguirlo son aptos o no conducen a su posesión. Ahora bien, el conocimiento de los fines últimos, la determinación de lo que exige la justicia trasciende por completo las posibilidades de un análisis científico. Es labor propiamente filosófica y no puede por ello ser cumplida por la Ciencia. Esta podrá llevar a cabo una crítica del derecho vigente desde el punto de vista técnico: para ello el instrumental de sus nociones y los medios de análisis de que dispone son perfectamente suficientes. Pero -aunque aspire a ello- no podrá de ningún modo ejercer una valoración desde el punto de vista de la justicia porque ésa es una labor exclusivamente filosófica (Martínez Doral, 1988, 25).

Si el Derecho es injusto se plantean entre otros los siguientes problemas:

1‥ La presunción de justicia está a favor del Derecho y del Estado en los regímenes políticos democráticos, por consiguiente la carga de la prueba de su injusticia corresponde al ciudadano-destinatario.

$2^{2}$. Si es válido en cuanto a su legitimidad tanto ética como democrática.

$3^{\circ}$. Un principio clásico decía que no existe nada más injusto que una ley injusta, precisamente porque se presenta con la máscara de la justicia.

También J. A. Ramos añade: "Si un Derecho es inicuo, injusto, inmoral, argumenta Hart, los principios en los que se inspire participarán de esa misma inmoralidad. El Derecho sudafricano de la época del Apartheid, por ejemplo, que implantó un injusto sistema de discriminación racial tendría como uno de 
sus principios implícitos el de que las personas de color son menos dignas de respeto que las de raza blanca, y obviamente éste es un principio inmoral" (Ramos Pascua, 2007, 25).

Una vez más comprobamos en el texto transcrito que el paso a la calificación de irracionalidad (contraposición con el gran género de la racionalidad) resulta muy fácil: tanto las personas de color como las blancas son seres racionales, pertenecientes a la misma especie humana racional, por lo que se opone a toda razón la discriminación fundada en el color de la piel. Lo mismo que afirmamos de su origen podemos sostenerlo de su finalidad: un Derecho que no tuviera ninguna conexión con el interés general, con la justicia, la libertad, la igualdad, etc., carecería de los caracteres de la racionalidad teórica y de la inteligibilidad político-social.

En esta misma línea insiste G. Peces-Barba: "Nuestras sociedades democráticas se distinguen por asumir una determinada concepción de la justicia, inspirada en los valores de dignidad, libertad, igualdad, seguridad y solidaridad y en la defensa de los derechos humanos. De acuerdo con esto, podremos afirmar que una norma es justa cuando satisface las exigencias de los anteriores contenidos" (Peces-Barba, 2007, 216-217).

Wojciech Sadurski nos habla incluso de una especie de "desencanto popular con esa democracia puramente "procedimental" que, como muestra la experiencia del siglo XX, no es una panacea para todos los males sociales, y a menudo carece de mecanismos autodefensivos suficientes contra aquellos que usan los procedimientos democráticos para perseguir fines inhumanos, opresivos y discriminatorios, y destruyen las instituciones democráticas en el proceso" (Sadurski, 2007, 49). La naturaleza de la democracia es, pues, más ética que matemática.

Algunos autores sostienen que el Derecho debe ser obedecido incluso por quienes discrepan moralmente de él, y ponen el ejemplo histórico de Sócrates que se sometió a una ley injusta cuyo quebrantamiento consideraba peor desde el punto de vista jurídico y moral que su cumplimiento. Proponemos que la solución correcta del caso debería ser la siguiente:

1․․ En primer lugar, como hemos hecho alusión, debe distinguirse entre una ley gravemente injusta (cuando atenta contra derechos fundamentales propios o de terceros), y levemente injusta (cuando no atenta contra derechos fundamentales).

$2^{\circ}$. La sentencia de los jueces de Atenas condenando a muerte a Sócrates mediante suicidio era gravemente injusta pues obligaba al filósofo a atentar contra su propia vida. Ni siquiera es necesario entrar en el tema de la culpabilidad de Sócrates respecto de los cargos que le imputaban, ni en el de la corrección de la aplicación de la legislación de Atenas vigente en la época.

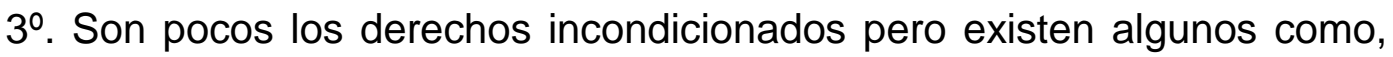
por ejemplo, no ser obligado al suicidio, no ser torturado, no ser calumniado, etc. 
4ํ․ Entre el ejercicio personal de estos derechos y la obligación de respetarlos en otros puede haber también casuísticas distintas. Por ejemplo, yo por alguna razón, podría lícitamente consentir en ser calumniado, pero jamás sería lícito, incondicional e inexcusablemente calumniar a otra persona.

5‥ En cambio, en el supuesto que analizamos la solución es la misma si el sujeto soy yo y mi derecho y si el sujeto es otro y su derecho: no es moralmente lícito someterme yo mismo a una ley que me obligue a suicidarme ni es moralmente lícito obligar legalmente a otros al suicidio. Por tanto sean cuales fueren las consecuencias no es lícito nunca suicidarse ni por decisión propia ni por imposición legal, por lo que se da realmente en este caso la obligación positiva de desobediencia. El suicidio por heroísmo de guerra es un caso distinto. El principio de evitar males mayores se aplica en los supuestos de leyes levemente injustas o también en algún caso específico (no en todos) de leyes gravemente injustas en que la víctima sea yo mismo y no otro.

6‥ Objetivamente, pues, el gran sabio Sócrates se equivocó e incurrió en legalismo inmoral aunque su percepción subjetiva era distinta. Fue la última equivocación pero no era la primera.

También era errónea su creencia (inducida por su gran sensibilidad moral), de que los que obran mal es siempre por ignorancia descartando siempre la posibilidad de malicia moral.

Muchas veces repetimos en Filosofía del Derecho que las funciones del Derecho son, entre otras, la valoración, la justificación y la racionalización del Derecho. Los tres términos son casi sinónimos puesto que la justicia es un valor que justifica la existencia del Derecho y la razón de ser del mismo. Observemos que el término justificación tiene dos sentidos: en primer lugar hace referencia al valor moral de la justicia. La justicia es la que justifica. Lo que aparentemente es una obviedad, actualmente no lo es tanto, si se olvida, por una parte, como ya hemos afirmado, que los valores jurídico-morales son los más objetivos en la escala jerárquica de valores; y si se recuerda, por otra parte, el gran número de "justificaciones" del Derecho de naturaleza voluntarista.

En segundo lugar, el término justificación hace referencia a la racionalidad: está justificado lo que tiene su razón de ser, lo que posee una motivación suficiente. Lo absurdo, lo sin sentido carece de justificación.

La conclusión de los dos significados del concepto de justificación es que lo injusto es al mismo tiempo inmoral e irracional, contrario a los imperativos ético-racionales de la razón práctica. El Derecho sin la justicia pretendería una autojustificación y, por tanto, una falsa justificación. Una teoría pura del Derecho, como propugna Kelsen, equivaldría a prescindir de los géneros, de la racionalidad y de la moralidad, al menos en el sentido que estamos describiendo. 


\title{
THE CIRCUNSTANCES OF THE CITIZENSHIF
}

\begin{abstract}
The three meanings of the term citizenship are deeply interrelated. Citizenship like citizens' group and as the citizens' rights, they depend (as for their social respect) of the citizenship like the citizens' civic qualities. The fundamental rights of the citizens are inherent to themselves as human people but they require of complex paradigms and ethical-juridical outlines to get to be respected. The legality characteristic of the rights of the citizens depends conceptually on the morality and of the rationality of the human fellows. The political and social citizenship that you/they are aspects of the artificial citizenship, is conditioned by the rationality y morality of the members of the political communities
\end{abstract}

Keywords: Citizenship. Morality. Political community. Rights. Rationality.

\section{AS CONDIÇÕES DA CIDADANIA}

\section{RESUMO}

Os três significados quanto ao fim da cidadania estão profundamente relacionados entre si. Cidadania, enquanto conjunto de cidadões e como direitos destes, depende (quanto ao seu aspecto social), da cidadania como qualidade cívica dos cidadões. Os direitos fundamentais dos cidadões são inerentes a eles mesmos, como pessoas humanas, pelo que necessitam de complexos paradigmas e esquemas ético-jurídicos para conseguirem ser respeitados. A juridicidade própria dos direitos dos cidadões depende da moralidade e da racionalidade dos sujeitos humanos. A cidadania política e a cidadania social, que são aspectos da cidadania jurídica, estão condicionadas pela racionalidade e pela moralidade dos membros da comunidade política.

Palavras-chave: Cidadania. Comunidade política. Direitos. Moralidade. Racionalidade.

\section{NOTAS}

Doutor em Direito. Teólogo. Filósofo. Professor de Filosofia do Directo na Universidade de Burgos, Espanha. E-mail: juanvegas@ubu.es. Endereço: Faculdades Integradas Ourinhos, Faculdade de Direito. C Marqués del Duero 7 - 09004 - Burgos - Espanha.

\section{REFERÊNCIAS}

Andorno, Roberto (1998): Bioética y dignidad de la persona, Madrid: Tecnos. 
Bellver Capella, Vicente (1994): Ecología: de las razones a los derechos, Granada: Tecnos

Bonetto, Susana, y Piñero, Mํㅡㄹ Teresa, (coords), (2004): Ciudadanía y costos sociales (Los nuevos marcos de regulación), Madrid: Dykinson.

Cortina Orts, Adela (1993): Ética aplicada y democracia radical, Madrid: Tecnos.

(1994): Ética de la sociedad civil, Madrid: Tecnos.

Colom Cañellas, A. J. y Rincón Verdera J.C. (2007): Educación, República y Nueva Ciudadanía, Valencia: Tirant lo Blanc.

Habermas, Jürgen (1999): La inclusión del otro (Estudios de teoría política), Barcelona: Paidós.

Galiana Saura, Ángeles (2008): La ley entre la razón y la experimentación, Valencia: Tirant lo Blanch.

Julios-Campuzano, Alfonso de (edtr), (2007): Ciudadanía y Derecho en la era de la globalización, Madrid: Dykinson.

Kant, Inmanuel (2000): Crítica de la razón práctica, Madrid: Alianza editorial.

Martínez Doral, José María (1988): "La racionalidad practica de la Filosofia del Derecho", Persona y Derecho 19.

Massini-Correas, Carlos Ignacio (1991): " El pensamiento contemporáneo acerca de los derechos humanos", Persona y Derecho 1.

Naval Durán, Concepción (2000):"Educación y Derechos Humanos", HUMANA IURA 10.

Naval, Concepción, y Herrero, Monserrat, (eds) (2006): Educación y ciudadanía en una sociedad democrática, Madrid: Encuentro.

Nieto, Alejandro (2007): Crítica de la razón jurídica, Madrid: Trotta.

Peces-Barba, Gregorio (2007): Educación para la ciudadanía y los derechos humanos, Obra colec., (Eusebio Fernández, Rafael de Asís y Francisco Javier Ansuátegui), Madrid: Espasa Calpe.

Ramos Pascua, José Antonio (2007): La ética interna del derecho, Bilbao: Desclée.

Rawls, Jhon (1979): Teoría de la justicia, Madrid: Fondo de Cultura Económica.

Sadurski, Wojciech (2007): "Legitimidad del Derecho, democracia y valores sustantivos", en Alfonso de Julios-Campuzano, edtr., Ciudadanía y Derecho en la era de la globalización, Madrid: Dykinson.

Spaemann, Robert (1988): "Sobre el concepto de dignidad humana", Persona y Derecho 19.

Sprute, Jürgen (2008): Filosofía política de Kant, Madrid: Tecnos.

Stammler, Rudolf (2007): Tratado de Filosofía del Derecho, Madrid: Reus.

Suárez Villegas, J. C. (1996): ¿Hay obligación moral de obedecer al Derecho?, Madrid: Tecnos

Velasco, Juan Carlos (2003): Para leer a Habermas, Madrid: Alianza. 
Zapata Barrero, Ricard (1996): "Ciudadanía y Estados de Bienestar o De la ingravidez de lo sólido en un mundo que se "desnewtoniza" social y políticamente, Sistema 130.

Zapatero, Virgilio y Garrido Gómez, María Isabel (2007): El Derecho como proceso normativo, Universidad de Alcalá de Henares.

Recebido para publicação: 10/09/2010

Aceito para publicação: 27/12/2010 